\title{
REGULATION, INCENTIVES AND GOVERNMENT POLICY: HOW DOES IT STIMULATE R\&D ENGINEERS' INNOVATIVE BEHAVIOURS IN MALAYSIAN BIOTECHNOLOGY SMEs?
}

\author{
Nurul Shamisza Sahrom*, Cheng Ling Tan and Sofri Yahya \\ Graduate School of Business, Universiti Sains Malaysia, 11800 Pulau Pinang, Malaysia \\ *Corresponding author: nurulshamisza@gmail.com
}

Published online: 30 December 2016

To cite this article: Sahrom, N.S., Tan, C.L., and Yahya, S. (2016). Regulation, incentives and government policy: How does it stimulates R\&D engineers' innovative behaviour in Malaysia biotechnology SMEs? Asian Academy of Management Journal, 21(Supp. 1), 49-73. http://dx.doi.org/10.21315/aamj2016.21.supp.1.3

To link to this article: http://dx.doi.org/10.21315/aamj2016.21.supp.1.3

\begin{abstract}
This study seeks to examine the relationship between regulation, incentives and government policy to $R \& D$ (research and development) engineers' innovative behaviour in Malaysia biotechnology SMEs. This research is empirical study where survey data was drawn from $218 R \& D$ engineers in biotechnology SMEs in Malaysia. The data were analysed using SmartPLS which is Structural Equation Modelling (SEM) tool. The result unfolds that government policy is positively and significantly associated with innovative behaviour. Nevertheless, regulation was found significant to innovative behaviour but demonstrates negative magnitude. On the other hand, incentives was insignificant to innovative behaviour. This in turn suggests that government policy is critical to foster innovative behaviour whereby the regulation enforcement that indicates disequilibrium possess by higher compliance cost be a disincentive for the $R \& D$ engineers to act innovatively. Contradict to previous studies, the insignificant relationship between incentives and individual innovative behaviour, possibly influence by lack of coordination, monitoring and vetting system with regards to the incentives distribution.
\end{abstract}

Keywords: regulation, incentives, government policy, innovative behaviour, R\&D engineers, biotechnology SMEs. 


\section{INTRODUCTION}

Biotechnology industry has become new promising economic driver in the age of bioeconomy era to spearhead Malaysia innovation performance and government realisation towards high income nation in 2020. The utilisation of biotechnology as a new source of technology to prosper multi-billion dollar industry such as pharmaceutical, agricultural, medical and alternative energy, propelled by constructive government intervention through effective policy measures, economic stimulus as well as dynamic innovation ecosystem that effectively link all business stakeholders such as government, biotechnology companies, academic institutions, public research institution and supporting agencies to boost research, development and commercialisation (R\&D\&C) activities in tandem with bioeconomy transformation programme (BTP) and national biotechnology policy (NBP). Towards the end, diligent commercialisation of innovative products and services are crucial to the successful of bioeconomy and more importantly, economically profitable for the government investment to ensure the sustainability of the government efforts in the industry future endeavour. Realizing this, human capital that possess higher degree of entrepreneurship is essential to fuel the prosperity of economic activities in the industry.

The entrepreneurial human capital particularly among R\&D profesionals has captured greater attention among scholars in knowledge intensive industry (Scott, 2006). In the similar manner, the emerging awareness on intrapreneurship concept has unveilled the neccessity of entrepreneurship among individual in the organisation as entrepreneurship conventionally related to the entrepreneurs or business owners (Antoncic, 2007). Consistent with Schumpeter's (Schumpeter, 1949) view, entrepreneur is the agent of change that stimulate the destruction economy by introducing new market through novel breakthrough thus upsetting the conventional ways of doing things. Towards the end, the entrepreneurial $R \& D$ professionals is facilitated by greater extent of innovativeness that spur economic activities in the industry. In contrast to ordinary R\&D professionals, the innovativeness of $R \& D$ professionals is equipped with proactive integration with their social environment in pursuing the opportunities that enable to deliver economic outcome. Their interaction with social environment will facilitate diffusion of knowledge, information and expertise thus enhance their creativity in generation of new ideas. In addition, the socialisation with the stakeholder in the industry such as government agency as well as venture capitalist would enhance the implementation of creative ideas particularly in getting the financial assistance which hardly funded by other financial institution due to high gestation period in biotechnology industry that posess significant uncertainty and risk to the financial institutions. This in turn emphasise the importance of innovative behaviour among 
$R \& D$ professionals in biotechnology industry to ensure the sustainability of the industry.

Theoretically, the extant research on innovative behaviour among employees is still embryonic (Agarwal, 2014) where intense effort has been done to conceptualised innovative behaviour from within-organisational perspective. Nevertheless, the behavioural scholars' early endeavours to understand individual innovative behaviour is initially stem from the perspective of individual factors such as personality and traits which mainly borrowed from creativity studies. The important of contextual factors has been acknowledged utmost significant to contribute individual innovative behaviour due to the fact individual innovative behaviour is socially-oriented. It is important, however, to recognize that current understanding on the impact of contextual factor to individual innovative behaviour is incomprehensive and limited to the microenvironment such as organisation and job variables hence mainly build from social exchange perspective (Blau, 1964) while macroenvironment property of the innovation such as institutions environment where the knowledge and other resources is magnificiently diffuse is neglected. In contrast to other industry, the dynamic innovative behaviour in high technology and knowledge intensive biotechnology industry requires exceptional level of the resources to possess innovative behaviour which naturally constrained by the organisation. Evidently, a study by Scott and Bruce (1994) found a negative insignificant relationship between resource supply in large R\&D facility and innovative behaviour due to threshold effect. Consistent with resource dependency theory (Pfeffer \& Salancik, 1978), this in turn demonstrates that the organisation requires resources from their external environment to foster innovative behaviour. Drawing from institutional theory (Scott, 2001), this study intends to examine the relationship between institutional factors to innovative behaviour among research and development (R\&D) engineers in biotechnology SMEs. This study contributes to the extant literatures in several ways. Firstly, despite focusing individual innovativeness from the perspective of microenvironment such as organisational tenets and job scope, this research add the extant literatures by modelling and examining the relationship between institutional elements such as regulation, incentives and government to innovative behaviour. Modelling institutional factors to individual innovative behaviour thus enable greater understanding on the extent of impact of institutional environment to enhance innovation capacity of R\&D professionals particularly in biotechnology industry. Secondly, this research attempts to integrate the institutional theory to innovative behaviour which relatively being taken for granted in previous studies due to the fact that the institutional environment is crucial to shape the social interaction between actors (North, 1990) in the interaction loop of the innovative system (Malmberg \& Power, 2005). Thirdly, this research will provide empirical evidence based on survey 
method that measure the innovative behaviour of the engineers and institutional factors based on the engineers' perception in spite of number of previous empirical studies are solely dependent on panel data analysis (Jaffe \& Palmer, 1997) and qualitative method. Gathering the data based on the individual perception on their environment will enhance greater understanding on their interaction with social environment (North, 1990).

\section{THEORETICAL BACKGROUND AND HYPOTHESES}

\section{Individual Innovative Behaviour}

Fundamentally, individual innovative behaviour is conceptualised as a complex (Janssen, 2000) and yet incontinous multistage process where individual may engage in any stage of innovative behaviour (Scott \& Bruce, 1994). It includes idea generation, idea promotion and idea realisation towards innovation outcome (Kanter, 1988; Scott \& Bruce, 1994). According to West and Farr (1990), individual innovative behaviour is termed as "all individual actions directed at the generation, introduction and application of beneficial novelty at any organisational level". In high technology industry, $R \& D$ professionals such as $R \& D$ engineers often been viewed as individual who possess greater degree of innovative behaviour (de Jong \& Den Hartog, 2008; Scott \& Bruce, 1994). It is due to the fact that commercialisation is paramount in high technology such as biotechnology industry which mainly drives by engineering of scientific knowledge into innovative outcomes. The commercialisation stems from the generation of creative ideas and solutions derived from the external cues and discrepancy in current applications. In a great extent of literatures, several scholars (Kanter, 1988; Van de Ven, 1986) emphasize individual innovative behaviour as the creation and execution of new ideas that requires greater integration with others in their external environments such as funding agency and academic institutions. As such, the realisation of the creative ideas requires coalition building and support with organisational members as well as external agency such as funders and regulatory bodies in order to seek for sponsorship and supports. Finally, the implementation of creative ideas is attained through model and prototype building that foster the commercialisation of innovative outcome. This in turn indicates that innovative behaviour is sociallyoriented in order to attain critical economic resources and opportunities to spur innovative ventures. 


\section{Determinants of Individual Innovative Behaviour}

The nature of innovative behaviour that is socially-oriented casts the important role of environment factors as substrates in the mechanism of innovative behaviour. Evidently, enormous amounts of studies on innovative behaviour has pictured organisational factors such as leadership (Odoardi, Montani, Boudrias \& Battistelli, 2015), organisational climate (Ren \& Zhang, 2015), leader-member exchange (Tastan \& Davoudi, 2015) and human resource practice (Dhar, 2015) are among prevalent organisational factors. However, a study by Awang, Sapie, Hussain, Ishak and Md. Yusuf (2014) demonstrates that work environment such as leadership, rewards, empowerment, recognition and facilities is insignificant in enhancing innovative behaviour among small and medium enterprises' (SMEs) employees in Malaysia. Interestingly, the employees' innovative behaviour in SMEs is stimulating in the work environment that foster learning (Awang et al., 2014). In contrast, Rahim, Salleh, Ahmad and Mustapha (2015) found that innovative behaviour among private sector employees in Malaysia is significantly contributes by the leadership style as well as knowledge management practices in the organisation. Even though leadership style has been acknowledged as essential to stimulate employees innovative behaviour, the inconsistency of the effect to employees innovative behaviour in SMEs probably due to their organic structure in SMEs that less complicated and lack communication barriers between employees and employers. Moreover, the lack of contextualisation in Awang et al., (2014) where innovative behaviour is adapted in general employees and industry in east coast of Malaysia constrained the generalisation of the organisational factors influence on individual innovative behaviour. It is due to the fact that subsectors as well as job factors plays a significant role in innovative behaviour. In particular, Bysted and Hansen (2015) found the difference on the innovative behaviour between public sector employees and private sector employees particularly in education, research, social services, post and telecom subsectors. However, the difference is neither relatively explained by the job factors such as autonomy and expectancy clarity nor organisational factors namely room for innovation and risk culture.

The overemphasised on the organisational and job factors, however, constrained the explanatory variance of innovative behaviour particularly in high technology SMEs. This research argues that the availability and accessibility towards critical economic resources such as knowledge and financial resources in the commercialisation is utmost importance thus emphasised the role of macroenvironment such as institutional factors. The strong link between R\&D and institutions (Vargo, Wieland \& Akaka, 2015; Wang, 2013) has been seen crucial particularly in biotechnology industry in Malaysia (Ahn \& York, 2011). Therefore, 
this research is conducted to examine the impact of institutional factors such as regulation, incentives and government policy to innovative behaviour.

\section{Institutional Factors}

The fast-changing environment has given weight to the role of institutions to drive the development and grow of small and medium enterprises (SMEs) particularly in biotechnology industry particularly in developing economy which substantially differs with developed economy. In essence, institutions are relatively related to the rules and regulation (North, 1990; Scott, 1995) as well as cognitive infrastructure (Scott, 1995) that devise the social interaction (North, 1990; Scott, 1995). Drawing from institutional theory (Scott, 2001), institutional environment such as rules, norms and culture is crucial to explain the individual behaviour (Scott, 2001; Tolbert \& Zucker, 1985). Specifically, the institutional environment will facilitate, spur and regulate the innovation process that cover generation, development, diffusion and utilisation of new knowledge and technology (Carlsson \& Stankiewicz, 1995) thus influence the pattern or dynamic of human behavior. The constructive institutions environment and arrangement would become enabler to the individual innovation as it capable to minimize the uncertainty and risk (Ahn \& York, 2011) facing by individual as well as reducing transaction cost in making the product available in the market (Welter \& Smallbone, 2011). Otherwise, it will demotivate and constrain the innovative performance of the individual.

Realizing that institutional environment is salient to innovation performance of the individual, substantial studies on the innovation performance of biotechnology industry equally captures the crucial role of institutional environment (Ahn \& York, 2011; Trippl \& Tödtling, 2008). Specifically, the emerging consensus that the innovation performance differs across geographical (Peng, Wang \& Jiang, 2008) put forth the distinct institutional environment associated in the national innovation system and regional innovation system. The ideal innovation system should embed with the constructive institutional environment that facilitates the diffusion of technology and market which essential to revive the creative destruction thus motivates the agency towards innovative behaviour.

Build upon institutional theory (Scott, 2001), this study proposes a model to investigate the relationship between institutional elements and innovative behaviour among engineers in biotechnology SMEs. Thorough review of literatures indicates that three main institutional elements such as regulation, incentives and government policy are crucial to stimulate innovative performance in high technology industry thus modelled in this research to stimulate innovative behaviour among engineers in biotechnology SMEs. 


\section{Regulation and Individual Innovative Behaviour}

Biotechnology industry is naturally being protected by the stern rules and legislation. It is embedded with strong secrecy level due to its complex nature in developing breakthrough and novel outcome by utilising life science technology as well as intensive cooperation with academic society where new knowledge is generated under longer gestation period and overpriced cost. In essence, the effect of regulation is double: constraint or regulative to individual behaviour (Scott, 1995). Conventionally, regulation has been perceived as constraint or barriers to innovation (Hall \& Bagchi-Sen, 2002; Trott, 2012) due to higher transaction cost associated with regulatory compliance. Nevertheless, the generalisation of negative effect between regulation and innovative behaviour is limited across industry. As compared to low innovative industry, high technology industry such as biotechnology is highly regulated industry. Therefore, it requires greater support of institutions such as government and other related agency to structure the regulation to incentivise the industry. Porter and van der Linde (1995) emphasize that the regulation empowers the stimulation of innovation which in turn counterbalance the compliance cost to a certain extent or remarkable extent. In fact, there is growing agreement among scholars that legal regulation and administrative environment can exert an important influence on innovation process at local, regional and national level (Ambec, Cohen, Elgie \& Lanoie, 2013; Shu, Zhou, Xiao \& Gao, 2014).

Even though there are studies demonstrate contradict influence of regulation on innovation (Bessen \& Hunt, 2007; Bessen \& Meurer, 2008), Porter and van der Linde (1995) contends that the well-designed regulation is a sine qua non. The purposeful and well-designed regulation is capable to stimulate creativity and innovation (Porter \& van der Linde, 1995; Welter \& Smallbone, 2011). Evidently, comprehensive implementation of environmental regulation was found crucial to enhance innovation performance in the development of green technology (Dechezleprêtre, Neumayer \& Perkins, 2015; Jaffe \& Palmer, 1997). It is stimulated by the substantial amount of knowledge and information reside in the social and institutional regulation ( $\mathrm{Lu}$, Tsang \& Peng, 2008; Porter, 1991) that provides opportunities towards development of new technology and incentivize the adoption of creative thinking. In addition, fair implementation of competition acts would provide motivation to the $R \& D$ engineers to produce novel and breakthrough ideas and solutions in order to break the stiffer competition (Aghion, Bloom, Blundell, Griffith \& Howitt, 2005). The constructive enforcement of regulation in relation to intellectual property acts as motivation and incentive to engage in the innovation behaviour which mainly derive from the competition in becoming the 'winner of the game' or the patent holder due to its higher return from monetizing their 
patent through licensing and direct utilisation (Wright, Pardey, Nottenburg \& Koo, 2007). Accordingly, this would simultaneously enhance the innovative behaviour by intensifying their research effort in developing new technology thus leads to innovative performance (Kemp \& Pontoglio, 2011). As such, the hypothesis of this study is conjectured as below:

H1a: Regulation will be positively associated with individual innovative behaviour.

\section{Incentives and Individual Innovative Behaviour}

Incentives often termed as subsidies, grants particularly research and commercialisation grants as well as tax incentives are among the essential and become the lifeblood in order to ensure the sustainability of biotechnology industry. The long gestation period in biotechnology industry forge the biotechnology companies to heavily rely on the financial assistance and incentives from the government due to the reluctance of commercial financial institution to fund their risky endeavour. Nevertheless, these incentives are provided by the government not only to bear their expensive operation cost but also to enhance the individual's innovation performance (Romijin \& Albaladejo, 2002; Kang \& Lee, 2008). Consistent with resource dependency theory (Pfeffer \& Salancik, 1978), the individual innovative performance in high technology industry is highly dependent on the availability of resources particularly financial resources towards the generation, promotion and implementation of ideas.

Specifically, the incentives such as R\&D and commercialisation grants would provide market-driven opportunity towards new venture and profitable R\&D area thus incentivised the innovative behaviour. Notwithstanding, the availability and accessibility of these incentives would enhance risk-taking and experimentation behaviour (Deak \& Peredy, 2015) in promoting and implementing their creative ideas. However, the ineffective distributions of incentives often undermines their significant role towards innovation behaviour (Holtz-Eakin, 2000; Lach, 2002; Santarelli \& Vivarelli, 2002). Ideally, the effective execution of incentives that yields significant impact to the national innovation performance is largely influenced by the selection process, monitoring and vetting system (Colombo, D'adda \& Piva, 2010). The robust incentives structure would stimulate healthy competition among biotechnology companies thus building innovative environment 
that value the novel and innovative creations. As such, the hypothesis of this study is hypothesised as below:

H1b: Incentives will be positively associated with individual innovative behaviour.

\section{Government Policy and Individual Innovative Behaviour}

Government policy constitutes the blueprint that emphasizes the government plan and initiative to their course of action. In order to produce innovative human capital, the government is responsible to provide innovative environment to the industry. Thus, innovative government policy become a trajectory to the development of innovative environment that involved various policy measures. Accordingly, Sharif (2012) emphasised that innovation policy that enable the diffusion of knowledge as well as other critical resources is crucial to fuel innovativeness. In fact, Kosters (2010) manifests that innovative policy should permit the tranferring of human and financial capitals along the social environment while Massa and Testa (2008) underlines that innovation policy should promotes dynamic collaboration between biotechnology companies and academic institutions. The effective government policy therefore, would facilitates the access towards tangible and intangible economic resources that subsequently become the opportunity and motivation in the competitive open innovation. Realising the importance of government policy in determining the direction and fate of the industry, therefore the hypothesis of this study is projected as below:

H1c: Government policy will be positively associated with individual innovative behaviour.

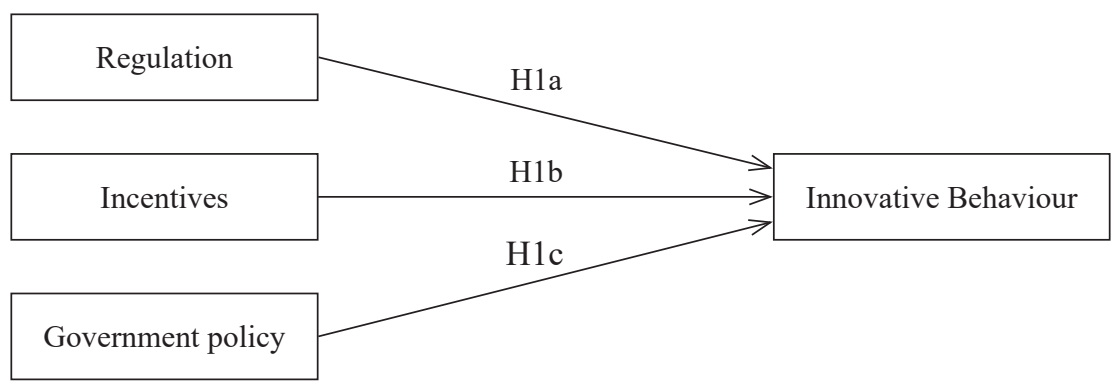

Figure 1 Research Model 


\section{METHODOLOGY}

\section{Sample}

The unit of analysis in this study is engineers that involved in research and development (R\&D) in biotechnology SMEs in Malaysia. The engineers are mainly from biotechnology SMEs that operating in agri biotechnology, healthcare biotechnology and industrial biotechnology. As suggested by Hair, Hult, Ringle and Sarstedt (2013), the minimum number of respondents is determined using three techniques namely the often-cited ten times rule (Barclay, Higgins \& Thompson, 1995) that take into account the ten times the largest number of arrow pointing at endogenous contruct which is individual innovativeness, Cohen's (1992) recommendations that take into consideration the statistical power and effect size as well as performing power analysis using G*Power software (Faul, Erdfelder, Lang \& Buchner, 2007). Based on these techniques, the minimum number of respondents in this study is 59 in order to obtain a statistical power of $80 \%$ for detecting the minimum $\mathrm{R}^{2}$ values of 0.25 with a $5 \%$ probability or error. The Cohen's (1992) recommendation is followed as this techniques provides higher number of respondents needed as compared to 30 respondents using ten times rule (Barclay et al., 1995) and 27 respondents when performed power analysis using $\mathrm{G}^{*}$ Power (Faul et al., 2007). As such, this research was using probability sampling as the list of biotechnology SMEs in Malaysia were gathered and compiled from several directories such as Small and Medium Enterprises Corporation (SMECorp), National Pharmaceutical Control Bureau (NPCB), Ministry of Health, Malaysia $(\mathrm{MOH})$, Malaysian Organization of Pharmaceutical Industry (MOPI), Malaysian Biotechnology Corporation (BiotechCorp), Federation of Malaysian Manufacturers (FMM), Halal Directory (JAKIM), Malaysian Palm Oil Board (MPOB) and Malaysian Technology Development Corporation (MTDC). The biotechnology SMEs were screened based on several criteria. Firstly, the biotechnology company should comply with the SMEs conditions forwarded by SMECorp such as employing not more than 200 full-time employees and their annual sales are below RM50 million (SMECorp, 2014). Secondly, the biotechnology SMEs must involve at least in one of these activities such as biotechnology R\&D, manufacturing their own-biotechnology productions or operation of biotechnology related processes, purchase of biotechnology products or processes from others, sales of biotechnology-related services, re-use of biological or renewal materials and involve in manufacturing sector (EPU, 2008). The list were then finalised by eliminating duplication and incompleteness. Due to the fact that the development of biotechnology industry in Malaysia is concentrated at the nine states located at the west coast of Malaysia due to the intense efforts has been given by the government 
in promoting and developing biotechnology as new technology in various regional economic transformation plan (NCER, Iskandar) and its close proximity with the research university, therefore, cluster sampling was employed in this research where the respondents were sampled in three regions in the west coast of Malaysia such as North (Perlis, Kedah, Penang and Perak), Central (Wilayah Persekutuan, Kuala Lumpur, Negeri Sembilan, Melaka) and South (Johor) regions.

\section{Data collection}

1056 questionnaires were distributed to a total of 352 biotechnology SMEs in the three regions. The questionnaire was distributed to the respondents using multimethod technique where some of the questionnaires were e-mailed and some of the questionnaires were self-administered. Participating biotechnology R\&D engineers were given two months to complete the questionnaires and the overall collection and distribution took three months to complete. After the stipulated period, 218 useable questionnaires were returned and subsequently analysed, representing a response rate of 20.7 percent.

\section{Measurement and Operationalisation of the Variables}

The predictor variables consist of institutional factors that include regulation, incentives and government policy. The regulation, incentives and government policy were measured using six item adapted from Blind (2012), six items adapted from Kolvereid and Obloj (1994) and seventeen items adapted from Huang, Schroder and Steffens (1999) respectively. These predictor variables were operationalise using five-point Likert scale ranging from (1) 'Strongly disagree' to (5) 'Strongly agree'. On the other hand, the dependent variable which is individual innovativeness was measured using nine items adopted from Janssen (2000). The individual innovativeness was then operationalised using seven-point Likert scale ranging from(1) 'Never' to (7) 'Always'. In spite of predictors and dependent variable, there are other extraneous variable such as individual demographic characteristic that might significantly influence individual innovativeness and known as control variable. The selection of the control variable was scrutinised in order to inhibit the misapplication of control statistic (Becker, 2005; Spector \& Brannick, 2011) that deflate the power of analysis. Based on previous studies, there were four demographic characteristics that significantly influence individual innovativeness. In particular, gender, age, job tenure and education level significantly associated with individual innovativeness (Janssen, 2000; 2004; 2005; Zhou, Zhang \& Montoro-Sanchez, 2011) thus were controlled in this study. 


\section{Method of Analysis}

This research employed Structural Equation Modelling (SEM) technique particularly SmartPLS (Ringle, Wende \& Will, 2005) due to several reasons. Firstly, this research is conjectural where the prediction of regulation, incentives and government policy on individual innovative behaviour is emphasised. Unlike covariance based techniques, the contributions of regulation, incentives and government policy to explain variance in individual innovative behaviour is crucial due to the scanty empirical research that explore these relationships. Hence, SmartPLS was believed suitable as SmartPLS is efficients in handling prediction model (Haenlein \& Kaplan, 2004) and provides vigorous structural estimations (Lohmöller, 1989; Reinartz, Haenlein \& Henseler, 2009). Secondly, the data in this study was following non-normal distribution and slightly skewed to the left particularly for regulation and incentives constructs. This happened in the present of outliers responses where some respondents disagreed with the conduciveness of the current implementation of regulation and incentives. As a matter of fact, SmartPLS was feasible in this study in accommodating not extreme non-normal data (Hair et al., 2013) as compared to covariance based technique.

\section{RESULT}

\section{Sample Profile}

$85.3 \%$ of the respondents are male while the remaining is female. The majority of the respondents are Malay (73.4\%) followed by Chinese (21.6\%), Indian (3.2\%) and other $(0.5 \%)$. The age of the respondents ranging from 23 to 58 years old with the average of 30.44 years $(\mathrm{SD}=6.86)$. Moreover, due to the fact that the respondents are professional employees, the majority (79.4\%) of the respondents are holding bachelor degree followed by master degree (8.7\%), diploma $(5.5 \%)$, doctorate $(3.7 \%)$ and other qualification $(2.7 \%)$ such as certificate or secondary school leavers (SPM/STPM). The average of the respondents' organisational tenure is 3.55 years $(\mathrm{SD}=2.46)$.

\section{Collinearity Assessment}

The assessment indicates that collinearity is not a serious problem among the predictors in this model when all VIF and tolerance values for both subpart of structural model are satisfied and well below the VIF threshold value of 5 and above the threshold value of 0.2 tolerance respectively (Hair et al., 2013) as demonstrated in below. 
Table 1

Collinearity assessment

\begin{tabular}{lcc}
\hline \multirow{2}{*}{ Predictors } & \multicolumn{2}{c}{ Collinearity Statistics } \\
\cline { 2 - 3 } & Tolerance & VIF \\
\hline Government policy & 0.759 & 1.318 \\
Incentives & 0.641 & 1.560 \\
Regulation & 0.792 & 1.263 \\
\hline
\end{tabular}

\section{Measurement Model Result}

The convergent validity was initially scrutinised by assessing their factor loading, composite reliability (CR) and average variance extracted (AVE). In essence, convergent validity demonstrates the extent or how well indicators in a latent construct correlate to each other. As depicted in Table 2 the factor loading for all constructs exhibits satisfactory loading when all of them a well above 0.5 threshold value as suggested by Hair et al., (2013). In addition, the AVE values which indicates the average percentage of variance explained by the item of the construct are sufficient and above 0.5 (Fornell \& Larcker, 1981) ranging from 0.538 to 0.653 . Meanwhile, the CR values are adequate when the values exceed 0.7 threshold value (Nunnally \& Bernstein, 1994) ranging from 0.840 to 0.944 thus illustrates the substantial homogeneity and consistency of the items within the reflective latent construct.

Moreover, the discriminant validity of the model was assessed to determine that the items are actually belongs to the construct and not related to other construct. As shown in Table 3, the measurement model demonstrates that discriminant validity of constructs is satisfactory when the values of square root AVEs (bold) are bigger as compared to the squared correlations horizontally and vertically. In addition, discriminant validity was established by examining the loading and cross loading. The data demonstrates that the loadings of the items in their respective construct are bigger as compared to the cross loading thus demonstrates that discriminant validity is not a problem in this model (Chin, 1998). Finally, it articulates that the indicators load higher in their constructs rather than other constructs. 
Table 2

Item loading, composite reliability (CR) and average variance extracted (AVE) for measurement model

\begin{tabular}{|c|c|c|c|c|}
\hline Construct & Measurement Items & Loading & $\mathrm{CR}^{\mathrm{a}}$ & $\mathrm{AVE}^{\mathrm{b}}$ \\
\hline \multirow[t]{3}{*}{ Regulation } & RN2 & 0.766 & 0.840 & 0.636 \\
\hline & RN3 & 0.824 & & \\
\hline & RN4 & 0.800 & & \\
\hline \multirow[t]{6}{*}{ Incentives } & IN1 & 0.641 & 0.873 & 0.538 \\
\hline & IN2 & 0.594 & & \\
\hline & IN3 & 0.802 & & \\
\hline & IN4 & 0.669 & & \\
\hline & IN5 & 0.775 & & \\
\hline & IN6 & 0.880 & & \\
\hline \multirow[t]{10}{*}{ Government Policy } & GP3 & 0.621 & 0.922 & 0.546 \\
\hline & GP4 & 0.610 & & \\
\hline & GP9 & 0.730 & & \\
\hline & GP10 & 0.806 & & \\
\hline & GP12 & 0.802 & & \\
\hline & GP13 & 0.779 & & \\
\hline & GP14 & 0.780 & & \\
\hline & GP15 & 0.656 & & \\
\hline & GP16 & 0.791 & & \\
\hline & GP17 & 0.777 & & \\
\hline \multirow[t]{9}{*}{ Innovative Behaviour } & INN1 & 0.767 & 0.944 & 0.653 \\
\hline & INN2 & 0.810 & & \\
\hline & INN3 & 0.778 & & \\
\hline & INN4 & 0.865 & & \\
\hline & INN5 & 0.699 & & \\
\hline & INN6 & 0.792 & & \\
\hline & INN7 & 0.864 & & \\
\hline & INN8 & 0.850 & & \\
\hline & INN9 & 0.835 & & \\
\hline
\end{tabular}

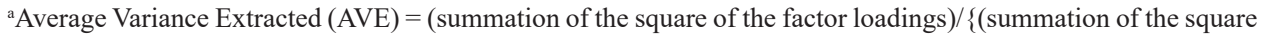
of the factor loadings) + (summation of the error variances) $\}$

${ }^{\mathrm{b}}$ Composite Reliability $(\mathrm{CR})=$ (square of the summation of the factor loadings $) /$ ( square of the summation of the factor loadings) + (square of the summation of the error variances) $\}$ 
Table 3

Discriminant validity of constructs

\begin{tabular}{lcccc}
\hline & GP & IN & INN & RN \\
\hline GP & $\mathbf{0 . 7 3 9}$ & & & \\
IN & 0.492 & $\mathbf{0 . 7 3 4}$ & & \\
INN & 0.454 & 0.166 & $\mathbf{0 . 8 0 8}$ & \\
RN & -0.033 & 0.285 & -0.177 & $\mathbf{0 . 7 9 7}$ \\
\hline
\end{tabular}

Diagonals (in bold) represent the square root of the average variance extracted while the other entries represent the squared correlations. GP=Government Policy, IN=Incentives, INN=Innovative behaviour, RN=Regulation.

\section{Structural Model Results}

In order to avoid confounding effect, the effect of control variables such as age, gender, job tenure and education level were assessed to the effect of individual innovative behaviour hence yield $0.084 \mathrm{R}^{2}$ value and insignificant relationships with individual innovative behaviour (Table 4). The $0.084 \mathrm{R}^{2}$ value indicates that $8.4 \%$ of explained variance in innovative behaviour is explained by the aforementioned control variables. The low $\mathrm{R}^{2}$ values as well as insignificant control variables to individual innovative behaviour demonstrate that the respondents differences in such variables does not possess distinct response pattern on individual innovative behaviour.

Table 4

Assessment of control variables

\begin{tabular}{lccc}
\hline \multirow{2}{*}{ Control Variables } & \multicolumn{3}{c}{ Innovative Behaviour } \\
\cline { 2 - 4 } & Beta & t-Value & $\mathrm{R}^{2}$ Value \\
\hline Age & 0.132 & 1.013 & \\
Gender & 0.136 & 1.023 & 0.084 \\
Job Tenure & 0.121 & 1.019 & \\
Education Level & 0.076 & 0.807 & \\
\hline
\end{tabular}

Next, the assessment of structural model that examines the hypotheses that have been set in this study reveals $\mathrm{R}^{2}$ value of 0.233 . In particular, $23.3 \%$ of variance in innovative behaviour of engineers in biotechnology SMEs is explained by regulation, incentives and government policy. By employing bootstrapping procedure with 5000 re-samples, only two institutional factors namely regulation and government policy were statistically significant to innovative behaviour while incentives was insignificant. Even though regulation is significant to innovative 
behaviour, nevertheless, the result shown that the effect of regulation $(\beta=-0.158$, $\mathrm{p}<0.05$ ) to innovative behaviour is negative which contradict to the expectation thus hypothesis 1 is rejected. On the other hand, government policy ( $\beta=0.456$, $\mathrm{p}<0.001$ ) was significant and positively associated with innovative behaviour hence hypothesis 3 is accepted. Unfortunately, hypothesis 2 is rejected when incentives was found statistically insignificant to innovative behaviour (Table 5).



Figure 2. Structural model

Table 5

Hypotheses testing

\begin{tabular}{clccc}
\hline Hypothesis & Relationship & Coefficients & t-value & Supported \\
\hline H1 & Regulation - Innovative Behaviour & -0.158 & $1.899^{*}$ & Not supported \\
H2 & Incentives - Innovative Behaviour & -0.014 & 0.122 & Not supported \\
H3 & Government Policy - Innovative & 0.456 & $7.078^{* * *}$ & Supported \\
& Behaviour & & & \\
\hline
\end{tabular}

\section{DISCUSSIONS, IMPLICATIONS AND CONCLUSION}

The goal of this study was to examine the impact of regulation, incentives and government policy to innovative behaviour among R\&D engineers in biotechnology SMEs. From the statistical standpoint, it reveals that the effect of regulation, incentives and government policy provide mixed results. Among these three factors, government policy was found positively and significantly related 
to innovative behaviour. In essence, government policy that portrays government commitment through intensive efforts and long term plan will provides the $R \& D$ professionals such as engineers with new opportunities and motivation thus stimulate their innovative behaviour. For instance, the intensive effort of Malaysia government towards bioeconomy has structurally materialised national biotechnology policy as well as national innovation system that constructively execute the government focus in developing industry capacity through financially and non-financially infrastructure building that facilitates the transferring of knowledge, resources and expertise. This in turn provides empirical evidence to the emerging qualitative research that government policy is essential to spur innovation performance in biotechnology industry (Ahn \& York, 2011; Trippl \& Tödtling, 2008) by enhancing the innovative behaviour of the R\&D professionals such as engineers. Unlike government policy, the effect of regulation to innovative behaviour is fascinating. The regulation was found significant to innovative behaviour, however, it demonstrates negative relationship with innovative behaviour which deviates many contemporary researches that addressed the positive relationship of regulation to innovation performance (Atkinson \& Ezell, 2012; Blind, 2012). Despite suggesting that regulation critical to innovative behaviour, the disequilibrium of regulation imposed by the government might provide threshold effect to the relationship. Due to the fact that innovation requires innovative environment that provides substantial degree of resources such as financial and knowledge (West \& Farr, 1990; Trippl \& Tödtling, 2008), the lacking of any resources would impede the innovation activities. Hence, further increment of the available resources without improving any deficiency would not enhance but detriment the innovative behaviour. Knowing that biotechnology industry is bounded by costly compliance cost of the regulative regime, the weak monitoring system that protect their breakthrough creation through Intellectual Property Right (IPR) as well as Competition Act increases the market barrier and transaction cost and by no means protect their costly investment in R\&D might deflate the incentive of regulation. As supported by rational choice theory (Scott, 2000), this scenario would diminish individual decision towards innovative behaviour as the cost associated to innovation exceeds the benefit gained. On the other hand, contradictory to previous studies (Guan \& Yam, 2015), the incentives such as tax relief, subsidies, grants and among others was found insignificant to innovative behaviour among engineers in biotechnology SMEs which intriguing due to the fact that these incentives are essential to drive $\mathrm{R} \& \mathrm{D}$ and commercialisation in knowledge intensive industry. This scenario might happen due to the unconstructive incentives distribution that unable to trigger competition due to the longer gestation period in biotechnology industry where the government will fund similar company over long period of time. The ineffective vetting system that monitors the progress and innovation achievement of the company would impede the motivation as well 
as competition among biotechnology companies (Colombo, Mustar \& Wright, 2010). In fact, the decentralisation and lack of coordination among fund providers in Malaysia would set difference requirement (Ahn \& York, 2011) thus inefficiently to spur innovative behaviour among engineers in biotechnology SMEs.

This study provides practical insight to biotechnology industry in several ways. Innovation is essential to biotechnology industry to ensure their competitiveness and sustainability particularly in the knowledge intensive era. Towards the end, human capital particularly R\&D professionals such as engineers should behave innovatively to prosper commercialisation of new products, services and method in biotechnology industry. The present study unveils that government policy is crucial to stimulate innovative behaviour among engineers in biotechnology industry. As such, the government should continuously offers and provides structurally plan and initiatives that promote greater collaboration among biotechnology SMEs, academic institutions and other related institutions that enable diffusion of innovation and resources in the innovation system. Moreover, the government should diligently work on the consumerism and market wise by creating consumer awareness towards local bio-based products and services hence creating demand, opportunity and healthy competition to the biotechnology SMEs. In addition the disparity of the regulation enforcement would disincentive the innovative behaviour among engineers in biotechnology industry. Therefore, the government should ensure that the high compliance cost should be complemented with the effective protection regime such as constructive Intellectual Property Right (IPR) and Competition Act to safeguard their investment and confidence which eventually motivate them to taking risk and venture innovative endeavor. With regards to the incentives, the negativity of incentives magnitude to innovative behaviour suggests that current incentives distribution practice is inefficient to stimulate the innovative behaviour among engineers in biotechnology SMEs. Therefore, in order to ensure the incentives are beneficial to the engineers as well as economically sustainable to the government by providing appropriate return on investment, the incentives should be distributed to the company that not only offering commercial value product and services but also economically value to ensure their long term success hence they would become independent and less reliance to government funding. Next, the government should provide robust vetting and monitoring system to stimulate competition among biotechnology companies. Even though various agencies are responsible to facilitates incentives to biotechnology companies, the government should ensure the coordination and organisation of incentives system is functionally centralised with consistent objectives to ensure that various incentives could realise the innovation performance. 
This research is confined with several limitations. Firstly, the single source data was employed in this research possibly contaminates the data with common method variance. Therefore, future study should consider multiple source data such as from managers and business owners. Secondly, this research was restricted to engineers in biotechnology SMEs thus might limit the generalisation of the result to other high technology industry and larger companies. As such, future study might validates the model to other high technology industry such as Information Technology (IT), communication, nanotechnology, automotive and so forth. Thirdly, this research is conducted to understand the influence of macroenvironment such as institutional factors to innovative behaviour. Realising this, future study should includes the organisational factors that reflects and enables by the institutional factors that modelled in this research in order to enhance the variance and understanding on individual innovative behaviour.

Given that innovative behaviour is heterogenous and elusive in nature, institutional factors such as regulation, incentives and government policy provides promising avenues in understanding the individual innovation. The aforementioned institutions is not only essential in the innovation performance at the organisational level but also fundamental in stimulating innovative behaviour particularly of the R\&D engineers. Hence, the government and policy makers should adapt their institutions practice in order to enhance the generation and implementation of innovation towards sustainable investment.

\section{REFERENCES}

Agarwal., U. A. (2014). Linking justice, trust and innovative work behaviour to work engagement. Personnel Review, 43(1), 41-73. http://dx.doi.org/10.1108/PR-022012-0019

Aghion, P., Bloom, N., Blundell, R., Griffith, R. \& Howitt, P. (2005), Competition and Innovation: An Inverted-U Relationship. Quarterly Journal of Economics, 120(2), 701-728. http://dx.doi.org/ 10.1093/qje/120.2.701

Ahn, J. M. and York, A. S. (2011). Resource-based and institution-based approaches to biotechnology industry development in Malaysia. Asia Pacific Journal of Management, 28, 257-275. http://dx.doi.org/10.1007/s10490-009-9147-2

Ambec, S., Cohen, M. A., Elgie, S. \& Lanoie, P. (2013). The Porter hypothesis at 20: Can environmental regulation enhance innovation and competitiveness? Review of Environmental Economics and Policy, 1-6. http://dx.doi.org/10.1093/reep/res016

Antoncic, B. (2007). Intrapreneurship: A comparative structural equation modeling study, Industrial Management \& Data Systems, 107(3), 309 - 325. http://dx.doi. org/10.1108/02635570710734244 
Atkinson, R. D. \& Ezell, S. J. (2012). Innovation economics: The race for global advantage. Yale Press.

Awang, A. H., Sapie, N. M., Hussain, M. H., Ishak, S. \& Md Yusof, R. (2014). Organizational learning and work environment: A formation of innovative work behavior at small medium enterprises (SMEs). Proceeding of The 11th International Conference on Intellectual Capital, Knowledge Management and Organisational Learning, $30-38$.

Barclay, D., Higgins, C., \& Thompson, R. (1995). The partial least square (PLS) approach to causal modeling, personal computer adoption and use as an illustration. Technology Studies: Special Issues on Research Methodology, 2(2), 285-324.

Becker, T.E.(2005). Potential problems in the statistical control of variables in organizational research: A qualitative analysis with recommendations. Organizational Research Methods, 8(3), 274-289. http://dx.doi.org/10.1177/1094428105278021

Bessen, J. \& Hunt, R. M. (2007). An empirical look at software patents. Journal of Economics \& Management Strategy, 16(1), 157-189. http://dx.doi.org/10.1111/ j.1530-9134.2007.00136.x

Bessen, J. \& Meurer, M. J. (2008). Do patents perform like property? Academy of Management Perspectives, 22(3), 8-20. http://dx.doi.org/10.5465/AMP.2008. 34587991

Blau, P. (1964). Power and exchange in social life. NY: John Wiley \& Sons.

Blind, K. (2012). The influence of regulation on innovation: A quantitative assessment for OECD countries. Research Policy, 41, 391- 400. http://dx.doi.org/10.1016/j. respol.2011.08.008

Bysted, R. \& Hansen, J. R. (2015). Comparing public and private sector employees' innovative behaviour: Understanding the role of job and organizational characteristics, job types and subsectors. Public Management Review, 17(5), 698-717. http://dx.doi.org/10.1080/14719037.2013.841977

Campbell, D. T. \& Fiske, D. W. (1959). Convergent and discriminant validation by the multi trait multi method matrix. Psychological Bulletin, 56, 81-105. http://dx.doi. org/10.1037/h0046016

Carlin, W. \& David, S. (2006). Macroeconomics: Imperfections, Institutions and Policies. Oxford University Press: Oxford.

Carlsson, B. \& Stankiewicz, R. (1995). On the nature, function and composition of technological systems, in Carlsson, B. (ed.) Technological systems and economic performance: the case of factory automation, Boston, Dordrecht and London, Kluwer Academic Publishers, 21-56. http://dx.doi.org/10.1007/978-94-0110145-5_2

Chin, W. W. (1998). The partial least squares approach to structural equation modeling. In G. A. Marcoulides (Ed.), Modern methods for business research (pp. 295-358). Mahwah, NJ: Lawrence Erlbaum Associates

Cohen, J. (1992). A power primer. Psychological Bulletin, 112(1), 155-159. http://dx.doi. org/10.1037/0033-2909.112.1.155

Colombo, M. G., D'adda, D. \& Piva, E. (2010). The contribution of university research to the growth of academic start-ups: An empirical analysis. Journal of Technology Transfer, 35, 113-140. http://dx.doi.org/10.1007/s10961-009-9111-9 
Colombo, M. G., Mustar, P., \& Wright, M. (2010). Dynamics of science-based entrepreneurship, Journal of Technology Transfer, 35, 1-15. http://dx.doi.org/ 10.1007/s10961-009-9114-6

De Jong, J. P. J. \& Den Hartog, D. N. (2008). Innovative Work Behavior: Measurement and Validation, Research Report of Scientific Analysis of Entrepreneurship and SMEs, Netherlands Ministry of Economic Affairs.

Deak, C. \& Peredy, Z. (2015). Policy framework conditions to foster "system innovation" with some illustration from an international perspective. Journal of Innovation Management, 14-24.

Dechezleprêtre' A., Neumayer, E. \& Perkins, A. (2015). Environmental regulation and the cross-border diffusion of new technology: Evidence from automobile patents. Research Policy, 44(1), 244-257. http://dx.doi.org/10.1016/j.respol.2014.07.017

Dhar, R. L. (2015). The effects of high performance human resource practices on service innovative behavior. International Journal of Hospitality Management, 51, 67-75. http://dx.doi.org/10.1016/j.ijhm.2015.09.002

EPU. (2008). $7^{\text {th }}$ Malaysia Plan. Retrieved July 20, 2012 from www.epu.gov.my/.

Faul, F., Erdfelder, E., Lang, A. G. \& Buchner, A. (2007). G*Power 3: A flexible statistical power analysis program for the social, behavioral, and biomedical sciences. Behavior Research Methods, 39, 175-191. http://dx.doi.org/10.3758/BF03193146

Fiske, D. W. (1982). Convergent-discriminant validation in measurements and research strategies. In D. Brinbirg \& L. H. Kidder (Eds.), Forms of validity in research (pp. 77-92). San Francisco: Jossey-Bass.

Fornell, C. \& Larcker, D. F. (1981). Evaluating Structural Equation Models with Unobservable Variables and Measurement Error. Journal of Marketing Research, 18(1), 39-50. http://dx.doi.org/10.2307/3151312

Guan, J. C. \& Yam, R. C. M. (2015). Effects of government financial incentives on firms' innovation performance in China: Evidences from Beijing in the 1990s. Research Policy, 44(1), 273-282. http://dx.doi.org/10.1016/j.respol.2014.09.001

Haenlein, M., \& Kaplan, A. M. (2004). A beginner's guide to partial least squares analysis. Understanding Statistics, 3, 283-297. http://dx.doi.org/10.1207/ s15328031us0304 4

Hair, J. F., Hult, G. T. M., Ringle, C. M. \& Sarstedt, M. A. (2013). Primer on partial least squares structural equation modeling (PLS-SEM), Thousand Oaks: Sage, 1-328.

Hall, L. A. \& Bagchi-Sen, S. (2002). A study of R\&D, innovation and business performance in the Canadian biotechnology industry. Technovation, 22(4), 231-244. http://dx.doi.org/10.1016/S0166-4972(01)00016-5

Holtz-Eakin, D. (2000). Public policy towards entrepreneurship. Small Business Economics, 15(4), 283-291. http://dx.doi.org/ 10.1023/A:1011153921409

Huang, X., Schroder, B. \& Steffens, P. (1999). The Chinese steel industry in transition: Industry perspective on innovation policy. $R \& D$ Management, 29(1), 17-24. http://dx.doi.org/10.1111/1467-9310.00113

Jaffe, A. B. \& Palmer, K. (1997). Environmental regulation and innovation: A panel data study, Review of Economics and Statistics, 79, 610-619. http://dx.doi. org/10.1162/003465397557196 
Janssen, O. (2000). Job demands, perception of effort-reward fairness and innovative work behavior. Journal of Occupational and Organizational Psychology, 73, 287-302. http://dx.doi.org/10.1348/096317900167038

Janssen, O. (2004). How fairness perceptions make innovative behavior more or less stressful, Journal of Organizational Behavior, 25(2), 201-215. http://dx.doi. org/10.1002/job. 238

Janssen, O. (2005). The joint impact of perceived influence and supervisor supportiveness on employee innovative behaviour. Journal of Occupational and Organizational Psychology, 78(4), 573-579. http://dx.doi.org/10.1348/096317905X25823

Kang, K. N. \& Lee, Y. S. (2008). What Affects The Innovation Performance in Small and Medium- Sized Enterprises (SMEs) in The Biotechnology Industry? An Empirical Study on Korean Biotech SMEs. Biotechnology Letters, 30(10), 16991704. http://dx.doi.org/ 10.1007/s10529-008-9745-y.

Kanter, R. M. (1988). When a thousand flowers bloom: Structural, collective and social conditions for innovation in organizations. In Straw, B. M. \& Cummings, L. L. (Eds.), Research in Organizational Behavior, 10, 123-167.

Kemp, R. \& Pontoglio, S. (2011). The innovation effects of environmental policy instruments. Ecological Economics, 72, 28-36. http://dx.doi.org/10.1016/j. ecolecon.2011.09.014

Kolvereid, L. \& Obloj, K. (1994). Entrepreneurship in emerging versus mature economies: An exploratory survey. International Small Business Journal, 12(4), 14-27 http:// dx.doi.org/10.1177/0266242694124001

Kosters, S. (2010). Subsidizing start-ups: Policy targeting and policy effectiveness. Journal of Industry, Competition and Trade, 10(3), 199-225. http://dx.doi.org/10.1007/ s10842-010-0083-0

Lach, S. (2002). Existence and persistence of price dispersion: An empirical analysis. Review of Economics and Statistics, 84, 433-444. http://dx.doi.org/ 10.3386/ w8737

Lohmöller, J. B. (1989). Latent Variable Path Modeling with Partial Least Squares. Heidelberg: Physica-Verlag. http://dx.doi.org/10.1007/978-3-642-52512-4

Lu, Y., Tsang, E. W. K. \& Peng, M. W. (2008). Knowledge management and innovation strategy in the Asia Pacific: Toward an institution-based view. Asia Pacific Journal of Management, 25(3), 361-374. http://dx.doi.org/ 10.1007/s10490-008-9100-9

Malmberg, A. \& Power, D. ( 2005). How do firms in clusters create knowledge, Industry and Innovation, 12(4), 409-431. http://dx.doi.org/10.1080/13662710500381583

Massa, S. \& Testa, S. (2008). Innovation and SMEs: Misaligned perspectives and goals among entrepreneurs, academics, and policy makers. Technovation, 28, 393-407. http://dx.doi.org/10.1016/j.technovation.2008.01.002

North, D. C. (1990). Institutions, Institutional Change, and Economic Performance. Cambridge: Cambridge University Press. http://dx.doi.org/10.1017/CBO97 80511808678

Nunnally, J. C. \& Bernstein, I. H. (1994). Psychometric theory (3rd ed.). New York: McGraw-Hill. 
Odoardi, C., Montani, F., Boudrias, J-S \& Battistelli, A. (2015). Linking managerial practices and leadership style to innovative work behavior: The role of group and psychological processes, Leadership \& Organization Development Journal, 36(5), 545-569. http://dx.doi.org/10.1108/LODJ-10-2013-0131

Peng, M. W., Wang, D. Y. L. \& Jiang, Y. (2008). An institution-based view of international business strategy: A focus on emerging economies. Journal of International Business Studies, 39(5), 920-936. http://dx.doi.org/10.1057/palgrave.jibs. 8400377

Pfeffer, J. \& Salancik, G. (1978). The External Control of Organizations: $A$ Resource Dependence Perspective. New York: NY. Haper and Row Publishers

Podsakoff, P. M. \& Organ, D. W. (1986). Self-reports in organizational research: Problems and prospects, Journal of Management, 12, 69-82. http://dx.doi. org/10.1177/014920638601200408

Podsakoff, P. M., MacKenzie, S. B., Lee, J.-Y. \& Podsakoff, N. P. (2003). Common method biases in behavioral research: A critical review of the literature and recommended remedies. Journal of Applied Psychology, 88, 879-903. http://dx.doi.org/10.1037/0021-9010.88.5.879

Podsakoff, P. M., MacKenzie, S. B., Lee, J.-Y. \& Podsakoff, N. P. (2012). Sources of method bias in social science research and recommendations on how to control it. Annual Review of Psychology, 63, 539-569. http://dx.doi.org/10.1146/annurevpsych-120710-100452

Porter, M. E. (1991). Towards a dynamic theory of strategy. Strategic Management Journal, 12(Special Issue: Fundamental Research Issues in Strategy and Economics), 95-117. http://dx.doi.org/ 10.1002/smj.4250121008

Porter, M. \& van der Linde, C. (1995). Toward a new conception of the environmentcompetitiveness relationship. Journal of Economic Perspective, 9(4), 97-118. http://dx.doi.org/10.1257/jep.9.4.97

Rahim, R. A., Salleh, N. F., Ahmad, S. F. S. \& Mustapha, R. M. R. (2015). Exploring the relationship between leadership style, knowledge management practices, and innovative behavior. Proceedings of the Colloquium on Administrative Science and Technology, 499-507. http://dx.doi.org/10.1007/978-981-4585-45-3_48

Reinartz, W., Haenlein, M. \& Henseler, J. (2009). An empirical comparison of the efficacy of covariance-based and variance-based SEM. International Journal of Research in Marketing, 26(4), 332-344. http://dx.doi.org/10.1016/j.ijresmar.2009.08.001

Ren, F. \& Zhang, J. (2015). Job stressors, organizational innovation climate, and employees' innovative behavior. Creativity Research Journal, 27(1), 16-23. http://dx.doi.org /10.1080/10400419.2015.992659

Ringle, C M., Wende, S. \& Will, A. (2005). SmartPLS 2.0 (M3) beta. http://www.smartpls. de.

Rogelberg, S. G., Allen, J. A., Shanock, L., Scott, C. W. \& Shuffler, M. (2010). Employee satisfaction with meetings: A contemporary facet of job satisfaction. Human Resource Management, 49, 149-172. http://dx.doi.org/10.1002/hrm.20339

Romijin, A. \& Albaladejo, M. (2002). Determinants of innovation capability in small electronics and software firms in Southeast England. Research Policy, 31, 10531067. http://dx.doi.org/10.1016/S0048-7333(01)00176-7 
Santarelli, E. \& Vivarelli, M. (2002), Is subsidizing entry an optimal policy? Industrial and Corporate Change, 11, 39-52. http://dx.doi.org/ 10.1093/icc/11.1.39

Schumpeter, J. A. (1949). Theory of economic development. Harvard University Press: Cambridge, Massachusetts.

Scott, W. R. (1995). Institutions and organizations. Thousand Oaks, CA: Sage.F

Scott, J. (2000). Rational choice theory. In G. Browning, A. Halcli \& F. Webster (Eds.), Understanding Contemporary Society: Theories of the Present. London: Sage

Scott, W. R. (2001). Institutions and organizations. Thousand Oaks, CA: Sage, 2nd ed.

Scott, A. J. (2006). Entrepreneurship, innovation and industrial development: Geography and the creative field revisited. Small Business Economics, 1-24. http://dx.doi. org/10.1007/s11187-004-6493-9

Scott, S. G. \& Bruce, R. A. (1994). Determinates of innovative behavior: A path model of individual innovation in the workplace. Academy of Management Journal, 137, 580-607. http://dx.doi.org/10.2307/256701

Sharif, N. (2012). Facilitating and promoting innovative entrepreneurship in Hong Kong: Theory and practice. Canadian Journal of Administrative Sciences, 29(2), 139153. http://dx.doi.org/10.1002/cjas. 230

Shu. C., Zhou, K. Z., Xiao, Y. \& Gao, S. (2014). How green management influences product innovation in China: The role of institutional benefits. Journal of Business Ethics, $1-15$.

SMECorp, (2014). New SME Definition. Retrieved July 4, 2014 from http://www.smecorp. gov.my/vn $2 /$.

Spector, P. E. \& Brannick, M. T. (2011). Methodological urban legends: The misuse of statistical control variables, Organizational Research Methods, 14(2), 287-305. http://dx.doi.org/10.1177/1094428110369842

Taştan, S. B. \& Davoudi, S. M. M. (2015). An examination of the relationship between leader-member exchange and innovative work behavior with the moderating role of trust in leader: A study in the turkish context. Procedia - Social and Behavioral Sciences, 181, 23-32. http://dx.doi.org/10.1016/j.sbspro.2015.04.862

Tolbert, P. S. \& Zucker, L. G. (1985). Institutional sources of change in the formal structure of organizations: the diffusion of civil service reform, 1880-1935, Administrative Science Quarterly, 30, 22-39.

Trippl, M. \& Tödtling F. (2008). From the ivory tower to the market place: Knowledge organizations in the development of biotechnology clusters. Journal of Regional Analysis and Policy, 38(2), 159-175.

Trott, P. (2012). Innovation management and new product development (4th ed.). Pearson Education Limited

Van de Ven, A. H. (1986). Central Problems in the Management of Innovation. Management Science, 32, 590-607. http://dx.doi.org/10.1287/mnsc.32.5.590

Vargo, S. L., Wieland, H. \& Akaka, M. A. (2015). Innovation through institutionalization: A service ecosystems perspective. Industrial Marketing Management, 44, 63-71. http://dx.doi.org/10.1016/j.indmarman.2014.10.008

Wang, C. (2013). Can institutions explain cross country differences in innovative activity? Journal of Macroeconomics, 37, 128-145. http://dx.doi.org/10.1016/j. jmacro.2013.05.009 
Welter, F. \& Smallbone, D. (2011). Institutional perspectives on entrepreneurial behavior in challenging environments. Journal of Small Business Management, 49(1), 107-125. http://dx.doi.org/10.1111/j.1540-627X.2010.00317.x

West, M. A. \& Farr, J. L. (1990). Innovation at work. In M. A. West \& J. L. Farr (Eds.), Innovation and creativity at work (pp. 3-13).

Wright, B. W., Pardey, P. G., Nottenburg, C. \& Koo, B. (2007). Agricultural innovation: investments and Incentives, Chapter in Evenson, R. E. and Pingali, P. eds. Handbook of Agricultural Economics, 3.

Zhou, Y., Zhang, Y. \& Montoro-Sanchez, A. (2011). Utilitarianism or romanticism: The effect of rewards on employees' innovative behaviour, International Journal of Manpower, 32(1), 81-98. http://dx.doi.org/10.1108/01437721111121242 